\title{
Structural Characterization of Melphalan Modified 2'-Oligodeoxynucleotides by Miniaturized LC-ES MS/MS
}

\author{
Bart Van den Driessche, Filip Lemière, Walter Van Dongen, \\ and Eddy L. Esmans \\ Nucleoside Research and Mass Spectrometry Unit, Department of Chemistry, University of Antwerp, Antwerp, \\ Belgium
}

\begin{abstract}
In this study a miniaturized LC coupled to electrospray tandem mass spectrometry was used to analyze modifications originating from the interaction between the chemotherapeutic agent melphalan and 2'-oligodeoxynucleotides. Low energy CAD product ion spectra gave information about the specificity of melphalan alkylation with regard to certain DNA sequences. These data can be very useful to estimate the risk in the development of secondary leukaemia as a result of a melphalan cure. In the study of the interaction between melphalan and $\mathrm{d}(\mathrm{GG})$, differentiation could be made between alkylation on the $5^{\prime}$-side and alkylation on the $3^{\prime}$-side, because of the presence or absence of the alkylated $w_{1}$ fragment in the low energy CAD spectra. In the other di-mers alkylation specificity for the different bases could be observed. Melphalan alkylation occurs in the sequence $\mathrm{G}>\mathrm{A}>\mathrm{C}>\mathrm{T}$. The study of the alkylated $\mathrm{d}(\mathrm{GGGG)}$ revealed the presence of mainly 5'-end alkylation. Furthermore studies were performed which investigated other melphalan treated di-, tetra-, hepta-, and octa-mers. (J Am Soc Mass Spectrom 2004, 15, 568-579) (c) 2004 American Society for Mass Spectrometry
\end{abstract}

$\mathrm{D}$ NA is a target for many xenobiotica and endogenous compounds. Electrophiles from either source can interact covalently with DNA with the formation of so called DNA adducts [1]. These adducts are believed to be the cause for an increased risk of cancer. One of these alkylating agents is the nitrogen mustard melphalan currently used as a chemotherapeutic agent in the treatment of malignant melanoma, multiple myeloma, lymphomas and ovarian carcinoma [2]. DNA adduct formation in perfectly healthy cells at the stage of primary cancer treatment might explain the development of a secondary leukaemia afterwards. It is a well known fact throughout literature that melphalan mainly alkylates the N-7 position in a guanine residue [3]. To the best of our knowledge, no information is available on the regioselectivity of melphalan alkylation in 2'-oligodeoxynucleotides and/or whole DNA strands. Therefore there were some important issues left as there are the degree of alkylation of $\mathrm{G}$ in relation to its position in the sequence, the influence of the neighbors on the degree of alkylation and the fragmentation patterns observed in melphalan modified 2'-oligodeoxynucleotides. Fur-

Published online February 5, 2004

Address reprint requests to Dr. E. L. Esmans, Nucleoside Research and Mass Spectrometry Unit, Department of Chemistry, University of Antwerp (RUCA-UIA), Groenenborgerlaan 171, Antwerp B-2020, Belgium. E-mail: eddy.esmans@ua.ac.be thermore can we detect $\mathrm{C}, \mathrm{A}$ and/or $\mathrm{T}$ adducts and what is the relation with earlier performed experiments on individual 2'-deoxynucleotides and -nucleosides $[4,5]$.

Electrospray mass spectrometry has become a viable technique for determining both the sequence specificity and the chemical structure of DNA modifications. By using this technology a lot of information was gathered on the adduct formation between potential carcinogens and individual 2'-deoxynucleotides (dNMPs) and -nucleosides (dNs). Furthermore modifications in whole DNA strands are studied after enzymatic digestion also resulting in the study of modified dNMPs and $\mathrm{dNs}$ [6]. However, this enzymatic digestion eliminates information related to the location of the adduct in the DNA sequence. In this paper we wish to describe a study of the melphalan modifications found in 2 '-oligodeoxynucleotides (dODNs). Modified dODNs of 2 up to 8 bases in length were studied with the aid of miniaturized liquid chromatography coupled to electrospray tandem mass spectrometry (LC ES-MS/ MS).

Next to the mass spectral investigation of intact oligodeoxynucleotides, sometimes a time-dependent exonuclease digestion can be used as an alternative or complementary technique to sequence oligodeoxynucleotides and hence to determine the position of the modification in larger ODNs [7]. In the latter 
(a)
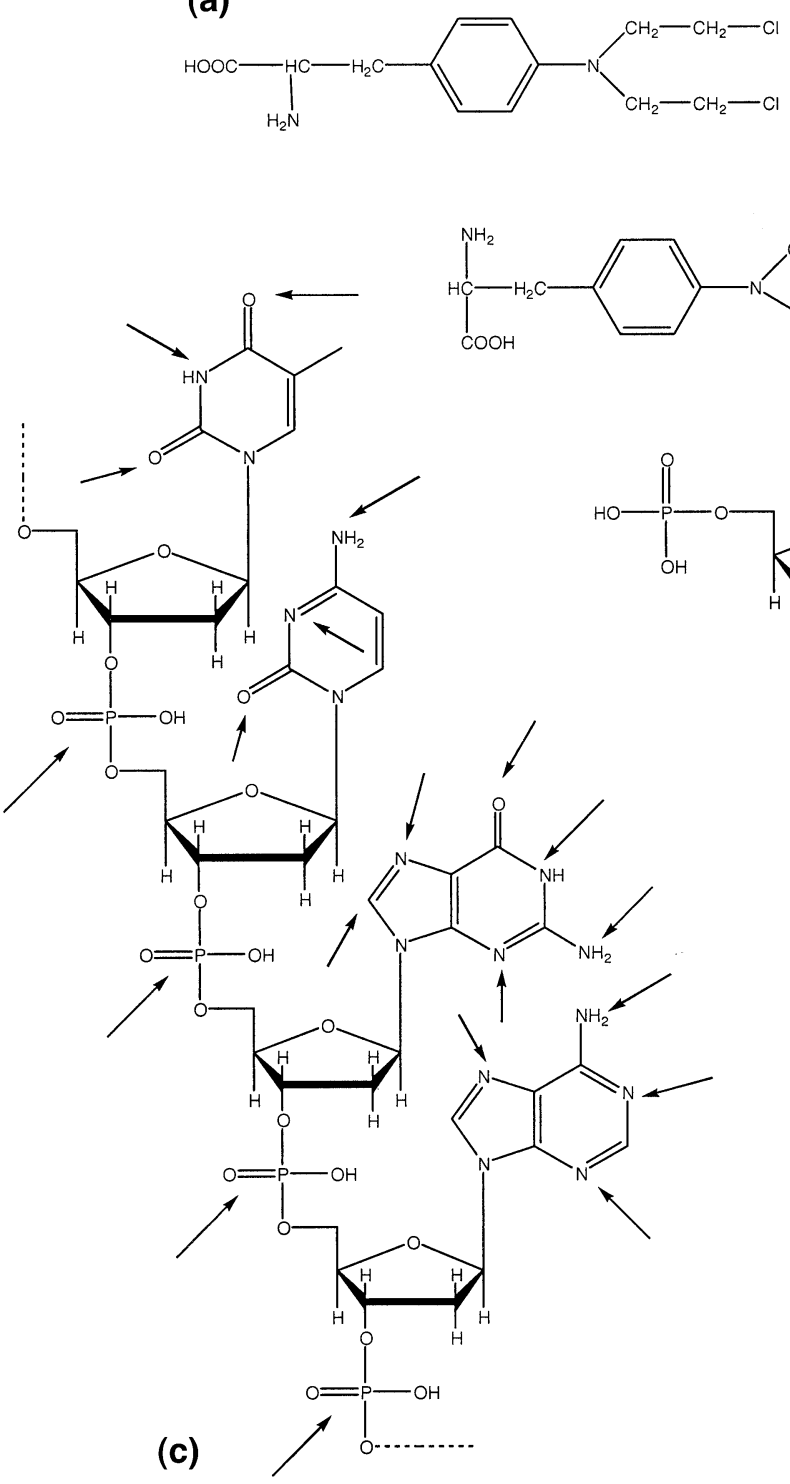

Figure 1. (a) Structure of melphalan; (b) the N-7 of guanine as a potential alkylation site; (c) Possible alkylation sites in dODNs.

method a $3^{\prime}$ - and/or 5'-exonuclease sequentially removes single nucleotides from the $3^{\prime}$ - or $5^{\prime}$-terminus, creating a mixture of ODNs that can be rapidly detected by MALDI-MS [8] or ES-MS [9]. In some cases enzymatic digestion is inhibited at the modification site which prevents full sequence information.

After the striking demonstration that polyanionic oligodeoxynucleotides could be transferred to the gas phase by electrospray ionization [10], mass spectrometry became an attractive approach for sequencing oligodeoxynucleotides. High quality electrospray spectra of oligodeoxynucleotides were recorded by Potier et al. [11], who demonstrated the use of electrospray in this field. Under ES MS/MS conditions, principal fragmentation pathways were elaborated by McLuckey et al. [12], Wan et al. [13, 14] and Wang et al. [15-17]. However, a clear distinction should be made between confirmation and de novo determination of a sequence [18]. Depending on oligodeoxynucleotide size, sample quantity and other factors, the various proposed methods differ somewhat in their capabilities for sequencing applications. To overcome the problem of sequencing larger oligodeoxynucleotides, one can use the "nearest neighbor" technique as described by Rozenski and McCloskey [19]. The identification of nearest neighbor residues in nucleic acids provides useful constraints on establishment of base composition and sequence and is potentially applicable to a range of structural problems involving synthetic and natural polynucleotides. Precursor-product relationships derived from small fragment ions produced in the high pressure ionization region of the instrument are measured. Measured mass values of dinucleotide- or other frag- 


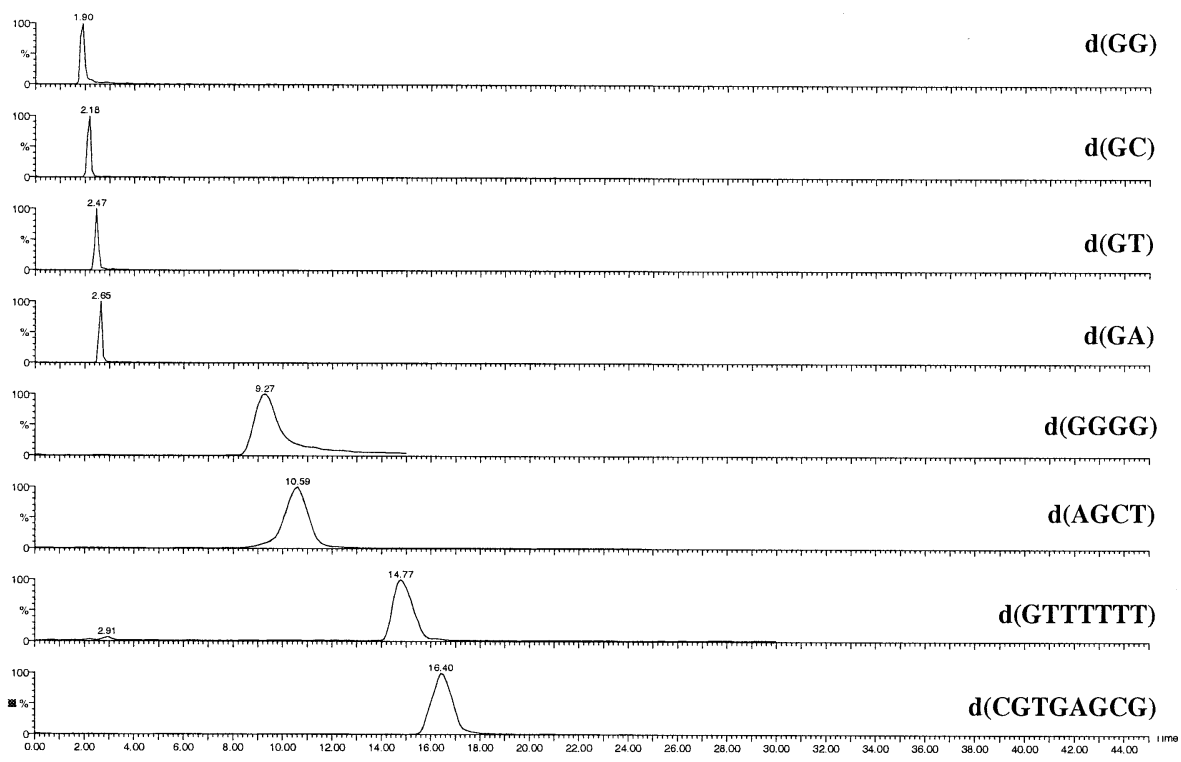

Figure 2. Chromatographic separation of a mixture of 2'-ODNs on a reversed phase analytical column $\left(\mathrm{C}_{18}, 300 \mu \mathrm{m}\right.$ i.d., $5 \mathrm{~cm}$ length): d(GG), d(GC), d(GT), d(GA), d(GGGG), d(AGCT), $\mathrm{d}(\mathrm{GTTTTTT})$, and d(CGTGAGCG). Mobile phases consisted of A: $400 \mathrm{mM} \mathrm{HFiP}$ in $\mathrm{H}_{2} \mathrm{O}$ (pH 7); B: 400 $\mathrm{mM}$ HFiP in $\mathrm{MeOH}$ ( $\mathrm{pH}$ 7); gradient elution was performed.

ments, which give rise to mononucleotide ions formed in the collision cell and transmitted by the second mass analyzer, establish the identities of residues adjacent to this mononucleotide ion. These fragment ions directly indicate the nearest neighbors of any selected nucleotide whether or not it is modified.

In this paper we focus on the preferential modification sites of the chemotherapeutic agent melphalan (Figure 1) in short 2'-oligodeoxynucleotides with different sequences. Chromatography based on a method described by Apffel et al. [20,21] was performed on the reaction mixtures before mass spectrometric analysis. A good HPLC separation and efficient electrospray ionization were obtained by using mobile phases containing of 1,1,1,3,3,3-hexafluoro-2-propanol (HFiP) as additive, adjusted to $\mathrm{pH} 7$ with triethylamine (TEA). During the separation, TEA formed ion pairs with the negatively charged phosphate groups of the oligodeoxynucleotide backbone. However, as the column effluent was electrosprayed and desolvated, the volatile $\mathrm{HFiP}$ was depleted at the droplet surface and the $\mathrm{pH}$ at the surface rised towards 10. At these higher $\mathrm{pH}$ value, the oligodeoxynucleotide-TEA ion pairs dissociated and the oligodeoxynucleotides were desorbed into the gas phase [20, 21].

\section{Experimental}

\section{Materials}

Water and methanol were purchased from Acros (Geel, Belgium). Melphalan, triethylamine, and 1,1,1,3,3,3hexafluoro-2-propanol were obtained from SigmaAldrich (Bornem, Belgium). The 2'-oligodeoxynucleotides were made to measure and desalted by Sigma-Genosys (Cambridgeshire, UK). All samples and mobile phases were filtered over a $0.2 \mu \mathrm{m}$ nylon syringe filter from Alltech (Lokeren, Belgium) just before analysis. The drug used in this study, melphalan, is listed as a carcinogen to humans. Appropriate precautions are necessary when handling this drug.

5,
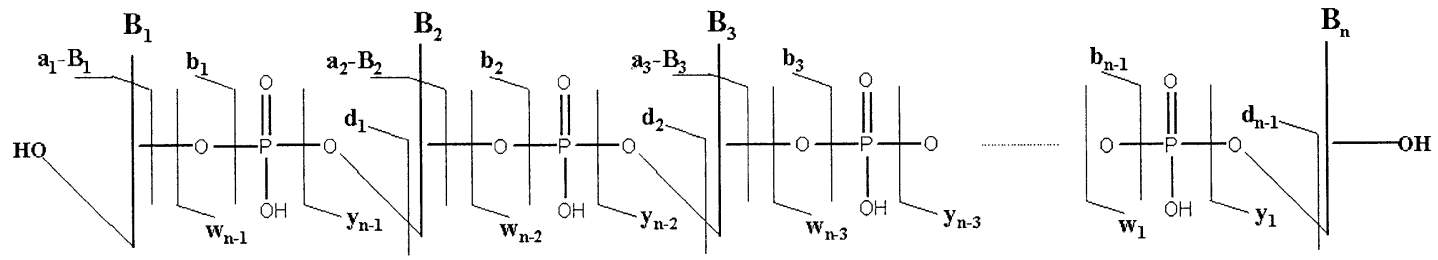

Figure 3. Oligonucleotide fragmentation nomenclature according to McLuckey et al. (Anal. Chem. 1991, 63, 18, 1971-1978) 
Table 1. Low energy CAD product ions of the unmodified 2'-ODN's. Low energy CAD spectra were obtained using a collision energy between 20 and $40 \mathrm{eV}$. The $\mathrm{w}$-fragmentation series is the most abundant one and seem to be the most reproducible one to characterize the eventual modified 2'-ODNs

\begin{tabular}{|c|c|c|c|c|c|c|c|c|c|c|c|c|c|c|c|c|}
\hline & {$[\mathrm{M}-\mathrm{H}]^{-}$} & $\mathrm{n}$ & $\begin{array}{c}\text { Charge } \\
\text { state }\end{array}$ & $a_{n}-B_{n}$ & $w_{n}$ & $y_{n}$ & $d_{n}$ & $\begin{array}{l}d_{n^{-}} \\
\mathrm{H}_{2} \mathrm{O}\end{array}$ & $\begin{array}{c}\text { [M- }^{-} \\
\mathrm{Gua}^{-}\end{array}$ & $\begin{array}{c}{[\mathrm{M}-} \\
\text { Ade }^{-} \\
\end{array}$ & $\begin{array}{c}\mathrm{M}^{-} \\
\mathrm{Cyt}^{-}\end{array}$ & $\begin{array}{c}\text { [M- }^{-} \\
\text {Thym] }^{-}\end{array}$ & $\begin{array}{c}\text { [Gua- } \\
\mathrm{H}]^{-}\end{array}$ & $\begin{array}{c}\text { [Ade- } \\
\mathrm{H}^{-}\end{array}$ & $\begin{array}{c}\text { [Cyt- } \\
\mathrm{H}^{-}\end{array}$ & $\begin{array}{c}\text { [Thym- } \\
\mathrm{H}]^{-}\end{array}$ \\
\hline \multirow[t]{11}{*}{ d(TTTGTTT) } & 2092 & 1 & -1 & & 321 & & 321 & 303 & & & & & 150 & & & 125 \\
\hline & & 2 & -1 & 401 & 625 & 545 & 625 & 607 & & & & & & & & \\
\hline & & & -2 & & 312 & & & & & & & & & & & \\
\hline & & 3 & -1 & 705 & 929 & 849 & 929 & 911 & & & & & & & & \\
\hline & & & -2 & & 464 & & & & & & & & & & & \\
\hline & & 4 & -1 & 1009 & & 1179 & & & & & & & & & & \\
\hline & & & -2 & 504 & 629 & 589 & & 620 & & & & & & & & \\
\hline & & 5 & -1 & & & & & & & & & & & & & \\
\hline & & & -2 & 669 & 781 & 741 & & 772 & & & & & & & & \\
\hline & & 6 & -1 & & & & & & & & & & & & & \\
\hline & & & -2 & 821 & & 893 & & & & & & & & & & \\
\hline \multirow[t]{11}{*}{ d(TTTTTG) } & 2092 & 1 & -1 & & 346 & & 321 & 303 & & & & & 150 & & & 125 \\
\hline & & 2 & -1 & 401 & 650 & 570 & 625 & 607 & & & & & & & & \\
\hline & & & -2 & & 325 & & & & & & & & & & & \\
\hline & & 3 & -1 & 705 & 954 & 874 & 929 & 911 & & & & & & & & \\
\hline & & & -2 & & 477 & & & & & & & & & & & \\
\hline & & 4 & -1 & 1009 & & 1179 & & & & & & & & & & \\
\hline & & & -2 & 504 & 629 & 589 & & 607 & & & & & & & & \\
\hline & & 5 & -1 & & & & & & & & & & & & & \\
\hline & & & -2 & 656 & 781 & 741 & & 759 & & & & & & & & \\
\hline & & 6 & -1 & & & & & & & & & & & & & \\
\hline & & & -2 & 808 & & 893 & & & & & & & & & & \\
\hline \multirow[t]{11}{*}{ d(ATTTTTT) } & 2075 & 1 & -1 & & 321 & & 330 & 312 & & & & & & 134 & & 125 \\
\hline & & 2 & -1 & 410 & 625 & 545 & & 616 & & & & & & & & \\
\hline & & & -2 & & 312 & & & & & & & & & & & \\
\hline & & 3 & -1 & 714 & 929 & 849 & & & & & & & & & & \\
\hline & & & -2 & & 464 & & & & & & & & & & & \\
\hline & & 4 & -1 & 1018 & 1234 & 1154 & & & & & & & & & & \\
\hline & & & -2 & 509 & 616 & 576 & & & & & & & & & & \\
\hline & & 5 & -1 & & & & & & & & & & & & & \\
\hline & & & -2 & 661 & 768 & 728 & & & & & & & & & & \\
\hline & & 6 & -1 & & & & & & & & & & & & & \\
\hline & & & -2 & & & 880 & & & & & & & & & & \\
\hline \multirow[t]{11}{*}{ d(TTTATTT) } & 2075 & 1 & -1 & & & 321 & & 303 & & & & & & 134 & & 125 \\
\hline & & 2 & -1 & 401 & 625 & 545 & & 607 & & & & & & & & \\
\hline & & & -2 & & 312 & & & & & & & & & & & \\
\hline & & 3 & -1 & 705 & 929 & 849 & & 911 & & & & & & & & \\
\hline & & & -2 & & 464 & & & & & & & & & & & \\
\hline & & 4 & -1 & 1009 & & 1163 & & & & & & & & & & \\
\hline & & & -2 & 504 & 621 & 581 & & & & & & & & & & \\
\hline & & 5 & -1 & & & & & & & & & & & & & \\
\hline & & & -2 & 661 & 773 & 733 & & 764 & & & & & & & & \\
\hline & & 6 & -1 & & & & & & & & & & & & & \\
\hline & & & -2 & 813 & & 885 & & & & & & & & & & \\
\hline \multirow[t]{10}{*}{$\mathrm{d}(\mathrm{CGTGAGCG})$} & 2450 & 1 & -1 & & 346 & & & 288 & & & & & 150 & 134 & 110 & 125 \\
\hline & & 2 & -1 & 386 & 635 & 555 & & 617 & & & & & & & & \\
\hline & & 3 & -1 & 715 & 964 & 884 & & 921 & & & & & & & & \\
\hline & & 4 & -1 & 1019 & & 1198 & & & & & & & & & & \\
\hline & & & -2 & & 638 & & & & & & & & & & & \\
\hline & & 5 & -1 & & & & & & & & & & & & & \\
\hline & & & -2 & & 674 & & & & & & & & & & & \\
\hline & & 6 & -1 & & & & & & & & & & & & & \\
\hline & & & -2 & 830 & & & & & & & & & & & & \\
\hline & & 7 & -1 & & & & & & & & & & & & & \\
\hline$d(G G)$ & 595 & 1 & -1 & & 346 & & 346 & & 444 & & & & 150 & & & \\
\hline$d(G A)$ & 579 & 1 & -1 & & 330 & & 346 & & 428 & 444 & & & 150 & 134 & & \\
\hline $\mathrm{d}(\mathrm{GC})$ & 555 & 1 & -1 & & 306 & & 346 & & 404 & & 444 & & 150 & & 110 & \\
\hline $\mathrm{d}(\mathrm{GT})$ & 570 & 1 & -1 & & 321 & 346 & & 419 & & & 444 & 150 & & & 125 & \\
\hline \multirow[t]{4}{*}{$\mathrm{d}(\mathrm{GGGG})$} & 1254 & 1 & -1 & & 346 & & 346 & 328 & & & & & 150 & & & \\
\hline & & 2 & -1 & 426 & 675 & 595 & & 657 & & & & & & & & \\
\hline & & 3 & -1 & 755 & 1004 & 924 & & & & & & & & & & \\
\hline & & & & & & & & & & & & & & & & (continued) \\
\hline
\end{tabular}


Table 1. (continued)

\begin{tabular}{|c|c|c|c|c|c|c|c|c|c|c|c|c|c|c|c|c|}
\hline & {$[\mathrm{M}-\mathrm{H}]^{-}$} & $n$ & $\begin{array}{c}\text { Charge } \\
\text { state }\end{array}$ & $a_{n}-B_{n}$ & $w_{n}$ & $y_{n}$ & $d_{n}$ & $\begin{array}{c}d_{n^{-}} \\
\mathrm{H}_{2} \mathrm{O}\end{array}$ & $\begin{array}{c}\text { [M- }^{-} \\
\text {Gua }^{-}\end{array}$ & $\begin{array}{c}{[\mathrm{M}-} \\
\text { Ade }^{-}\end{array}$ & $\begin{array}{c}\text { [M- }^{-} \\
\text {Cyt }^{-}\end{array}$ & $\begin{array}{c}\text { Thym }^{-} \\
\text {Thym }^{-}\end{array}$ & $\begin{array}{c}\text { [Gua- } \\
\mathrm{H}]^{-}\end{array}$ & $\begin{array}{c}\text { [Ade- } \\
\mathrm{H}]^{-}\end{array}$ & $\begin{array}{l}\text { [Cyt- } \\
\mathrm{H}]^{-}\end{array}$ & $\begin{array}{c}\text { [Thym- } \\
\mathrm{H}^{-}\end{array}$ \\
\hline \multirow[t]{3}{*}{$\mathrm{d}(\mathrm{GCGC})$} & 1174 & 1 & -1 & & 306 & & 328 & & & & & 150 & & 110 & & \\
\hline & & 2 & -1 & 426 & 635 & 555 & & 617 & & & & & & & & \\
\hline & & 3 & -1 & 715 & 924 & 844 & & & & & & & & & & \\
\hline \multirow[t]{4}{*}{$\mathrm{d}(\mathrm{GACT})$} & 1173 & 1 & -1 & & 321 & & & & & & & 1046 & 150 & 134 & & 125 \\
\hline & & 2 & -1 & 426 & 610 & 530 & 641 & & & & & & & & & \\
\hline & & 3 & -1 & 739 & 923 & 843 & & & & & & & & & & \\
\hline & & & -2 & & 461 & & & & & & & & & & & \\
\hline \multirow[t]{4}{*}{$\mathrm{d}(\mathrm{CGAT})$} & 1173 & 1 & -1 & & 321 & & & 288 & & 1037 & & 1046 & 150 & 134 & 110 & 125 \\
\hline & & 2 & -1 & 386 & 634 & 554 & 617 & & & & & & & & & \\
\hline & & 3 & -1 & 715 & 963 & 883 & & & & & & & & & & \\
\hline & & -2 & & 481 & & & & & & & & & & & & \\
\hline \multirow[t]{5}{*}{$\mathrm{d}(\mathrm{TACG})$} & 1173 & 1 & -1 & & 346 & & & 303 & 1021 & 1037 & & 1046 & 150 & 134 & 110 & 125 \\
\hline & & 2 & -1 & 401 & 635 & 555 & & & & & & & & & & \\
\hline & & & -2 & & 317 & & & & & & & & & & & \\
\hline & & 3 & -1 & 714 & 948 & 868 & & & & & & & & & & \\
\hline & & & -2 & & 473 & & & & & & & & & & & \\
\hline \multirow[t]{4}{*}{$\mathrm{d}(\mathrm{TAGC})$} & 1173 & 1 & -1 & & 306 & & & & 1021 & 1037 & & 1046 & 150 & 134 & & 125 \\
\hline & & 2 & -1 & 401 & 635 & 555 & & & & & & & & & & \\
\hline & & 3 & -1 & 714 & 948 & 868 & & & & & & & & & & \\
\hline & & & -2 & & 473 & & & & & & & & & & & \\
\hline \multirow[t]{5}{*}{$\mathrm{d}(\mathrm{AGCT})$} & 1173 & 1 & -1 & & 321 & & & & & 1037 & & 1046 & 150 & 134 & 110 & 125 \\
\hline & & 2 & -1 & 410 & 610 & 530 & 659 & 641 & & & & & & & & \\
\hline & & & -2 & & 305 & & & & & & & & & & & \\
\hline & & 3 & -1 & 739 & 939 & 859 & & & & & & & & & & \\
\hline & & & -2 & & 469 & & & & & & & & & & & \\
\hline \multirow[t]{13}{*}{ d(GTTTTTT) } & 2092 & 1 & -1 & & 321 & & 346 & & & & & & 150 & & & 125 \\
\hline & & 2 & -1 & 426 & 625 & 545 & & 632 & & & & & & & & \\
\hline & & & -2 & & 312 & & & & & & & & & & & \\
\hline & & 3 & -1 & 730 & 929 & 849 & & & & & & & & & & \\
\hline & & & -2 & & 464 & & & & & & & & & & & \\
\hline & & & -3 & & & & & & & & & & & & & \\
\hline & & 4 & -1 & 1034 & & 1154 & & & & & & & & & & \\
\hline & & & -2 & 516 & 616 & 576 & & & & & & & & & & \\
\hline & & & -3 & & 410 & & & & & & & & & & & \\
\hline & & 5 & -1 & & & & & & & & & & & & & \\
\hline & & -2 & & 768 & 728 & & & & & & & & & & & \\
\hline & & 6 & -1 & & & & & & & & & & & & & \\
\hline & & & -2 & & & 880 & & & & & & & & & & \\
\hline \multirow[t]{11}{*}{ d(TGTTTTT) } & 2092 & 1 & -1 & & 321 & & 321 & 303 & & & & & 150 & & & 125 \\
\hline & & 2 & -1 & 401 & 625 & 545 & 650 & 632 & & & & & & & & \\
\hline & & -2 & & 312 & & & & & & & & & & & & \\
\hline & & 3 & -1 & 730 & 929 & 849 & 954 & 936 & & & & & & & & \\
\hline & & & -2 & & 464 & & & & & & & & & & & \\
\hline & & 4 & -1 & 1034 & 1234 & 1154 & & & & & & & & & & \\
\hline & & & -2 & & 616 & 576 & & & & & & & & & & \\
\hline & & 5 & -1 & & & & & & & & & & & & & \\
\hline & & & -2 & 669 & 768 & 728 & & & & & & & & & & \\
\hline & & 6 & -1 & & & & & & & & & & & & & \\
\hline & & & -2 & 821 & & 893 & & & & & & & & & & \\
\hline
\end{tabular}

\section{Methodology}

Interaction of 2'-Oligodeoxynucleotides with Melphalan

The 2'-oligodeoxynucleotides were dissolved in water to a final concentration of $1 \mathrm{mg} / \mathrm{ml}$. A melphalan stock solution of $1 \mathrm{mg} / \mathrm{ml}$ in water was made just before reaction. A $2^{\prime}$-ODN solution $(100 \mu \mathrm{l})$ was reacted with $100 \mu \mathrm{l}$ of the melphalan stock solution. As a consequence, the final concentration of the start components in this reaction mixture was $0.5 \mathrm{mg} / \mathrm{ml}$. The reaction mixtures were kept at a temperature of $37{ }^{\circ} \mathrm{C}$ for a period of $1 \mathrm{~h}$. From these reaction mixtures $1 \mu \mathrm{l}$ was directly injected on the analytical column for analysis.

\section{Mass Spectrometric Conditions}

Electrospray (-) mass spectra were recorded on a Q-TOF 2 instrument (Micromass, Manchester, UK). The mass spectrometer was equipped with a pneumatically 
Table 2. Characteristic low energy CAD product ions of the melphanlan modified 2'-ODNs as described in the text. The product ions were used to identify the alkylation site. Low energy CAD spectra were obtained using a collision energy between 20 and $40 \mathrm{eV}$

\begin{tabular}{|c|c|c|}
\hline $2^{\prime}-d(O D N)$ & $\begin{array}{c}\text { Observed } \\
\text { characteristic } \\
\text { product ion }\end{array}$ & $m / z$ \\
\hline $\mathrm{d}(\mathrm{AGCT})$ & {$[\mathrm{w} 2+\mathrm{mel}]-$} & 878 \\
\hline $\mathrm{d}(\mathrm{GCGC})$ & {$[\mathrm{d} 1-\mathrm{H} 2 \mathrm{O}+\mathrm{mel}]-$} & 597 \\
\hline $\mathrm{d}(\mathrm{GGGG})$ & {$[\mathrm{a} 2-\mathrm{B} 2+\mathrm{mel}]-$} & 695 \\
\hline \multirow[t]{2}{*}{ d(GTTTTTT) } & {$[\mathrm{d} 1+\mathrm{mel}]-$} & 615 \\
\hline & [d2 + mel]- & 919 \\
\hline \multirow[t]{2}{*}{ d(TTTTTTG) } & [w1 + mel]- & 615 \\
\hline & [w2 + mel]- & 919 \\
\hline Base & $\begin{array}{c}\text { Depurination } \\
\text { products }\end{array}$ & \\
\hline $\bar{G}$ & [Gua + mel]- & 418 \\
\hline$A$ & [Ade + mel]- & 402 \\
\hline $\mathrm{C}$ & [Cyt + mel]- & 378 \\
\hline
\end{tabular}

assisted Z-spray source. The MS system was hyphenated with a capillary LC system (CapLC, Waters, Millford, UK). A six-way injection valve was used to load the analytical column. The CapLC system was connected to a FAMOS micro-injection system and the standard electrospray probe was used. The voltage on the stainless steel electrospray capillary was set at -3.5 $\mathrm{kV}$. Low energy collision activated dissociation spectra were recorded using argon as collision gas (gas cell pressure $3.6 \times 10^{-3} \mathrm{mbar}$ ). The source temperature was kept at $120^{\circ} \mathrm{C}$. The flow rate of the nebulizing gas $\left(\mathrm{N}_{2}\right)$ and the drying gas $\left(\mathrm{N}_{2}\right)$ was 30 and $280 \mathrm{l} / \mathrm{h}$, respectively. Low energy CAD spectra were recorded using a variable collision energy of 20 to $40 \mathrm{eV}$. Scan time was set at $1 \mathrm{~s}$, with an interscan delay of $0.1 \mathrm{~s}$ when a mass range of $\mathrm{m} / \mathrm{z} 100$ to 1000 was scanned. When a mass range of $\mathrm{m} / \mathrm{z} 100$ to 2500 was scanned, the scan time was set at $1.5 \mathrm{~s}$ with an interscan delay of $0.1 \mathrm{~s}$. Wherever low energy CAD data are mentioned in the text, these are the combined results from the fragmentation of the $[\mathrm{M}-\mathrm{H}]^{-}$, the $[\mathrm{M}-2 \mathrm{H}]^{2-}$ and the $[\mathrm{M}-3 \mathrm{H}]^{3-}$. This was dependent on the size of the observed molecule. The smaller di-mers only showed a $[\mathrm{M}-\mathrm{H}]^{-}$in very good abundance while the octa-mers were mainly triply ionized.

\section{Chromatographic Conditions}

The reversed phase analytical column $\left(\mathrm{C}_{18}, 300 \mu \mathrm{m}\right.$ i.d., $5 \mathrm{~cm}$ length) was purchased from LC-Packings (Amsterdam, The Netherlands). $1 \mu \mathrm{L}$ of the filtered reaction mixture was injected on the analytical column and eluted with gradient elution. The mobile phase consisted of $400 \mathrm{mM} \mathrm{HFiP,} \mathrm{adjusted} \mathrm{with} \mathrm{TEA} \mathrm{to} \mathrm{a} \mathrm{pH}$ of 7. Therefore, a stock solution of $800 \mathrm{mM} \mathrm{HFiP}$ was prepared and adjusted to a $\mathrm{pH}$ of 7 . For mobile phase $\mathrm{A}$ the stock solution was diluted with water to a final concentration of $400 \mathrm{mM}$ HFiP. To prepare mobile phase B, the stock solution was diluted with methanol likewise to a final concentration of $400 \mathrm{mM}$ HFiP. The starting conditions of the mobile phase were $98 \%$ A, $2 \%$ B. These were maintained for $2 \mathrm{~min}$. Then a linear gradient was started reaching $20 \%$ A, $80 \%$ B in $18 \mathrm{~min}$. These condi-

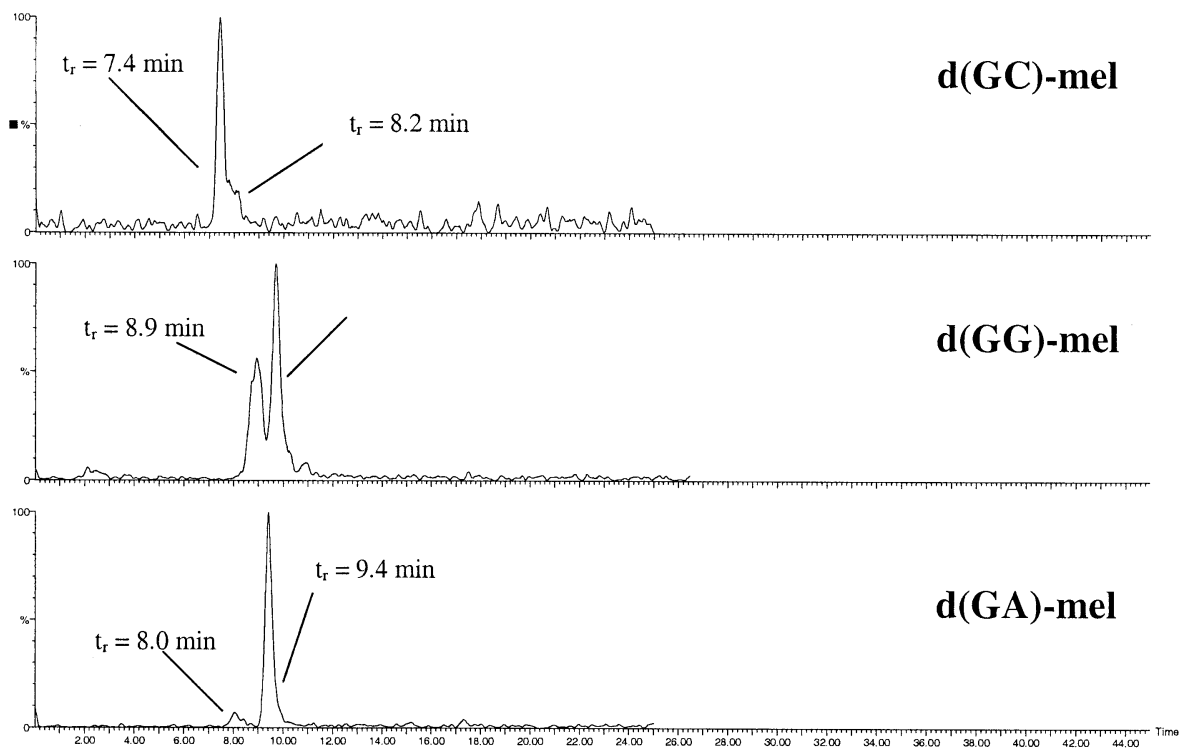

Figure 4. Chromatographic separation of the melphalan alkylated di-mers d(GC), d(GG), and d(GA) on a reversed phase analytical column $\left(\mathrm{C}_{18}, 300 \mu \mathrm{m}\right.$ i.d., $5 \mathrm{~cm}$ length). Mobile phases consisted of $\mathrm{A}$ : $400 \mathrm{mM}$ HFiP in $\mathrm{H}_{2} \mathrm{O}$ (pH 7); $\mathrm{B}: 400 \mathrm{mM}$ HFiP in $\mathrm{MeOH}$ ( $\mathrm{pH}$ 7). The starting conditions of the mobile phase were $98 \%$ A, $2 \%$ B. These were maintained for $2 \mathrm{~min}$. Then a linear gradient was started reaching $20 \% \mathrm{~A}, 80 \% \mathrm{~B}$ in $18 \mathrm{~min}$. These conditions were maintained for $10 \mathrm{~min}$. Isomers can be seen which represents alkylation on each of the present nucleobases. 

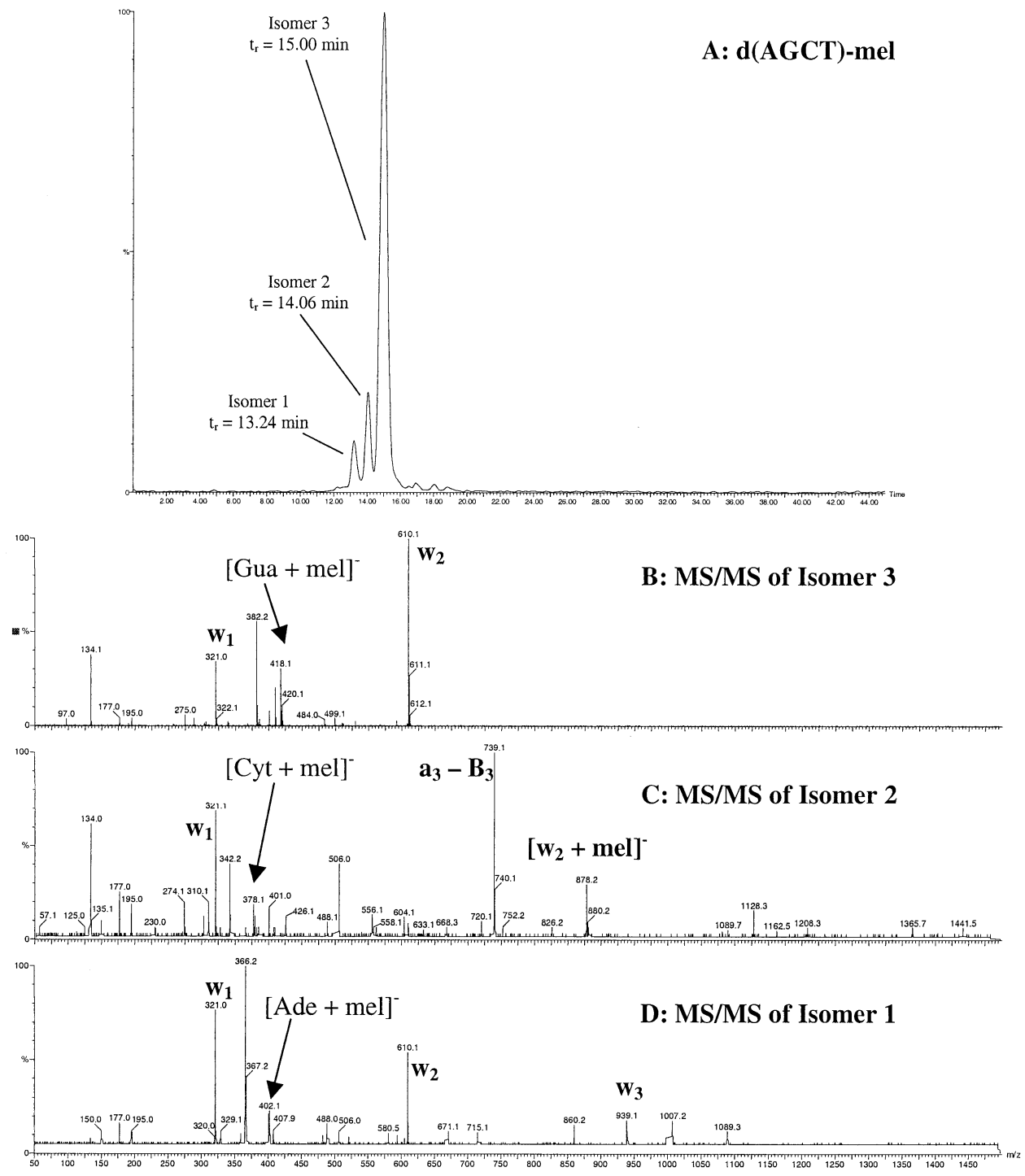

Figure 5. Trace A: Chromatographic separation of the reaction mixture of a melphalan alkylated tetra-mer $\mathrm{d}(\mathrm{AGCT})$ on a reversed phase analytical column $\left(\mathrm{C}_{18}, 300 \mu \mathrm{m}\right.$ i.d., $5 \mathrm{~cm}$ length). Mobile phases consisted of A: $400 \mathrm{mM}$ HFiP in $\mathrm{H}_{2} \mathrm{O}$ (pH 7); B: $400 \mathrm{mM}$ HFiP in $\mathrm{MeOH}$ (pH 7). The starting conditions of the mobile phase were $98 \% \mathrm{~A}, 2 \% \mathrm{~B}$. These were maintained for $2 \mathrm{~min}$. Then a linear gradient was started reaching $20 \% \mathrm{~A}, 80 \% \mathrm{~B}$ in $18 \mathrm{~min}$. These conditions were maintained for $10 \mathrm{~min}$. Isomers can be seen which represents alkylation on the adenine- (Trace D), cytosine- (Trace C), and guanine residue (Trace C). Alkylation on the thymine base could not be observed.

tions were maintained for $10 \mathrm{~min}$. After this the analytical column was equilibrated with the starting conditions before a next experiment was performed. The flow rate over the analytical column was $8 \mu \mathrm{L} / \mathrm{min}$.

\section{Detection Limit of 2'-Oligodeoxynucleotides}

The detection limit was determined by injection of $1 \mu \mathrm{L}$ of standard diluted 2'-oligodeoxynucleotides (dGG, dGGGG, and dGTTTTTT) onto the developed miniaturized LC-MS system. The high content of HFiP and TEA had an influence on the detection limit of the compounds. However we aimed at a balance between detection limit and chromatographic performance. Us- ing the system as described modified or unmodified 2 '-oligodeoxynucleotides could be detected with a LOD of $5 \times 10^{-10} \mathrm{~g}$.

\section{Results}

\section{Chromatographic Separation of 2'-Oligodeoxynucleotides}

As already shown by Apffel et al. [20,21], the described LC technique in combination with ES-MS suppresses effective cation adduct formation and result in high resolution separations of relatively short oligodeoxynucleotides. As shown in Figure 2 separations were 

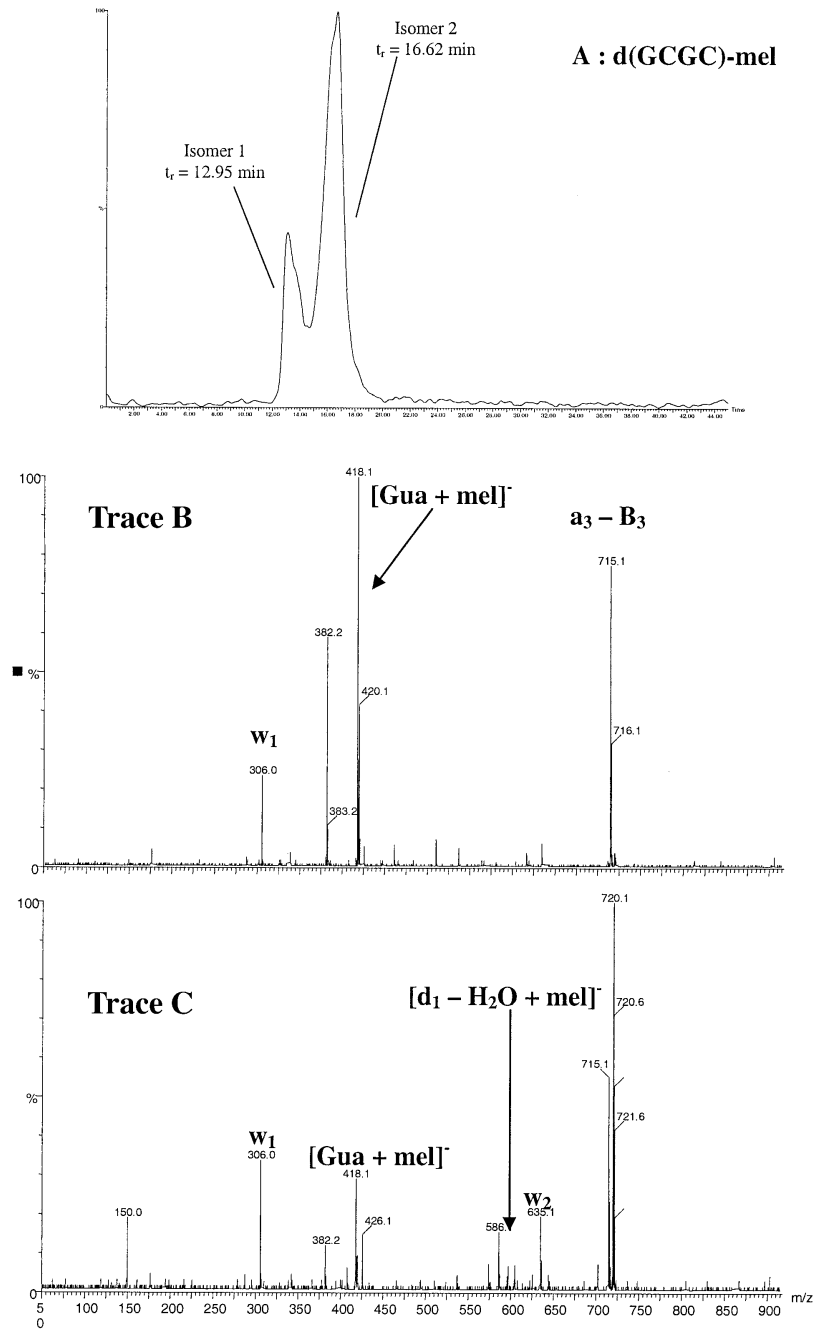

Figure 6. Trace A: Chromatographic separation of the reaction mixture of a melphalan alkylated tetra-mer d(GCGC) on a reversed phase analytical column $\left(\mathrm{C}_{18}, 300 \mu \mathrm{m}\right.$ i.d., $5 \mathrm{~cm}$ length). Mobile phases consisted of A: $400 \mathrm{mM} \mathrm{HFiP}$ in $\mathrm{H}_{2} \mathrm{O}$ (pH 7); B: 400 $\mathrm{mM}$ HFiP in $\mathrm{MeOH}$ ( $\mathrm{pH}$ 7). The starting conditions of the mobile phase were $98 \%$ A, $2 \%$ B. These were maintained for $2 \mathrm{~min}$. Then a linear gradient was started reaching $20 \%$ A, $80 \%$ B in $18 \mathrm{~min}$. These conditions were maintained for $10 \mathrm{~min}$. Isomers can be seen which represents alkylation on the 5'-G- (Trace C) and $3^{\prime}-\mathrm{G}-$ residue (Trace $\mathrm{B}$ ).

possible in mixtures of short oligodeoxynucleotides with different sequences as well as in mixtures of oligodeoxynucleotides differing in length. The four different di-mers were separated in a limited time window. Their retention times $t_{r}$ were $d(G G): 1.90$ min; $\mathrm{d}(\mathrm{GC}): 2.18 \mathrm{~min}$; $\mathrm{d}(\mathrm{GT}): 2.47 \mathrm{~min}$, and $\mathrm{d}(\mathrm{GA}): 2.65 \mathrm{~min}$. Mixtures of oligodeoxynucleotides with different lengths were more easily separated as can be seen on the chromatogram given in Figure 2. The 4-mer $d$ (GGGG) has a $t_{r}$ of $9.27 \mathrm{~min}$, while another 4-mer $d(A G C T)$ has a $t_{r}$ of 10.59 min. The 7-mer $\mathrm{d}$ (GTTTTTT) has a $\mathrm{t}_{\mathrm{r}}$ of $14.77 \mathrm{~min}$. The 8-mer d(CGTGAGCG) was eluting with a retention time of 16.40 $\min$.

\section{Sequencing of 2'-Oligodeoxynucleotides}

Performing low energy CAD spectra showed typical $\mathrm{w}_{\mathrm{n}}, \mathrm{y}_{\mathrm{n}}, \mathrm{d}_{\mathrm{n}}-\mathrm{H}_{2} \mathrm{O}$, and $\mathrm{a}_{\mathrm{n}}-\mathrm{B}_{\mathrm{n}}$ fragments. The oligodeoxynucleotide fragmentation nomenclature (see also reference [22]) as depicted in Figure 3 was used, according to the nomenclature used in the original papers of McLuckey et al. [23]. This figure shows the major fragmentations that occur upon collision activation. Internal fragments are also a common feature in these product ion spectra. The various cleavages around the phosphodiester backbone are already described by McLuckey et al. [12]. Procedures for interpretation of CID mass spectra of oligodeoxynucleotides were developed explicitly for applications in which the entire sequence is a priori unknown. In the examples described in this manuscript the sequence was known and this somewhat eases the problem. Nevertheless the fragmentation data from the unmodified 2 -oligodeoxynucleotides were used to interpret the data from the melphalan treated oligodeoxynucleotides. All oligodeoxynucleotides had a free hydroxyl group at the $3^{\prime}$ - and $5^{\prime}$-termini. Most straightforward were the results observed for the 2-mers. Typical fragments could be explained by the loss of the base moiety, $\mathrm{w}$-fragments, $\mathrm{y}$-fragments, a-B-fragments, and d-fragments. In Table 1 the results were summarized for all compounds studied: The 2-mers, the 4-mers, the 7-mers, and the 8-mers. This table helps the reader to interpret the product ion spectra from the unmodified 2'-ODNs as well as from the modified $2^{\prime}$-ODNs. The major fragmentation series were the $\mathrm{w}$-series, which were reproducible enough to sequence unknown $2^{\prime}$-ODNs or to determine the modification site in modified 2'-ODNs. Table 2 shows the typical product ions of some melphalan modified dODNs. These ions were used to identify the alkylation position as mentioned in the respective paragraphs when the topic is described.

\section{Melphalan Alkylation of Dinucleotides}

In previous studies we already showed a preferred melphalan alkylation of the guanine base in 2'deoxynucleosides, 2'-deoxynucleotides, and calf thymus DNA [4,5]. Next to this alkylation was observed at the adenine- and the cytosine moiety. However, due to its low nucleophilicity, thymidine alkylation could hardly be detected. By choosing a specific oligodeoxynucleotide sequence, the difference in alkylation specificity could be observed. Interpreting the ES-MS and ES-MS/MS data of alkylated d(GG), d(GA), d(GC), and $\mathrm{d}(\mathrm{GT})$ one could notice that 2 isomers were formed in $d(G G), d(G A)$ and $d(G C)$. One isomer was the result of alkylation of the guanine moiety, while the other isomer represented alkylation of the other base. As can be seen in Figure 4, in the case of $d(G G)$ a 11:14 alkylation ratio (Isomer 1/Isomer 2; $[\mathrm{M}-\mathrm{H}]^{-}=863$ ) could be calculated by comparing the peak areas of the corresponding chromatographic signals. The product 

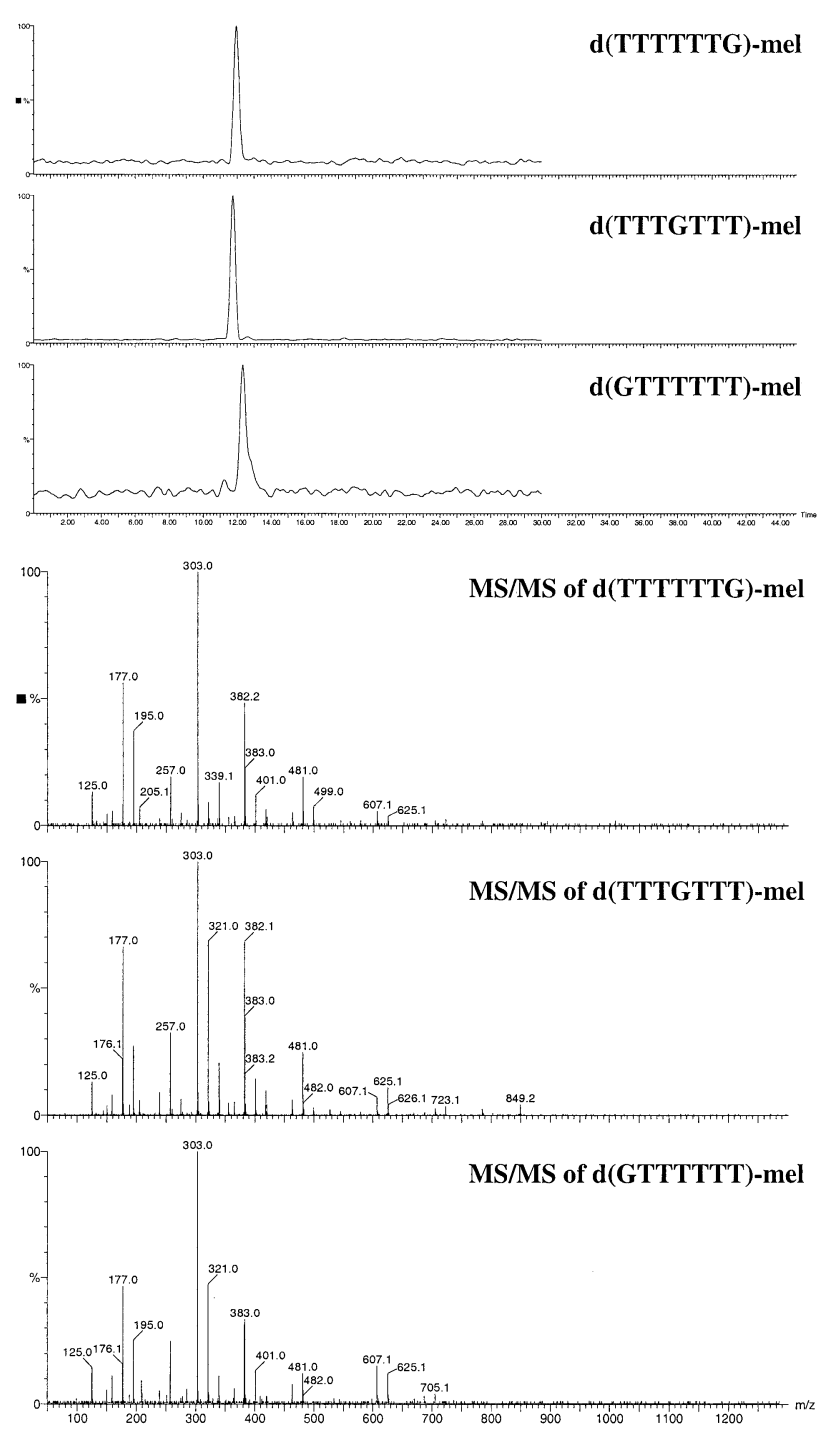

Figure 7. Chromatographic separation of the reaction mixture of the melphalan alkylated hepta-mers d(GTTTTTT), d(TTTGTTT), and d(TTTTTTG) on a reversed phase analytical column $\left(\mathrm{C}_{18}, 300\right.$ $\mu \mathrm{m}$ i.d., $5 \mathrm{~cm}$ length). Mobile phases consisted of A: $400 \mathrm{mM}$ HFiP in $\mathrm{H}_{2} \mathrm{O}(\mathrm{pH}$ 7); $\mathrm{B}: 400 \mathrm{mM}$ HFiP in $\mathrm{MeOH}(\mathrm{pH}$ 7). The starting conditions of the mobile phase were $98 \%$ A, $2 \%$ B. These were maintained for $2 \mathrm{~min}$. Then a linear gradient was started reaching $20 \%$ A, $80 \%$ B in $18 \mathrm{~min}$. These conditions were maintained for 10 min. One signal can be seen which represents alkylation on the guanine residue. Low energy CAD product ion spectra were performed on the $[\mathrm{M}-4 \mathrm{H}]^{4-}$ ions.

ion spectra showed the presence of the $\mathrm{w}_{1}$ fragment in the second isomer $\left(t_{r} 9.7 \mathrm{~min}\right)$ but not in the first isomer $\left(t_{\mathrm{r}} 8.9 \mathrm{~min}\right)$. This could be explained by alkylation of the $\mathrm{w}_{1}$ fragment which did not occur in the second isomer. This also meant that there was a slight preference for alkylation of the $G$ at the $5^{\prime}$-end in $d(G G)$. However, no positive proof was found concerning the $3^{\prime}$-terminal fragment ion carrying the modification.

Analyzing the data from the alkylated $\mathrm{d}(\mathrm{GA})$ showed an alkylation ratio of 1:15 (Isomer 1/Isomer 2). MS/MS data from the first isomer $\left(\mathrm{t}_{\mathrm{r}} 8.0 \mathrm{~min}\right)$ with [M $-\mathrm{H}]^{-}=847$ showed the presence of a product-ion at $m / z 402$ which could be explained by the alkylation of the adenine base residue. Analogously in the MS/MS spectra of the second isomer $\left(t_{\mathrm{r}} 9.4 \mathrm{~min}\right)$ an alkylated guanine residue could be found at $m / z$ 418. A study of the melphalan alkylated $\mathrm{d}(\mathrm{GC})$ showed an even lesser amount of alkylation on the cytosine moiety compared with the neighboring guanine moiety. An alkylation ratio of 1:26 could be observed. The low energy CAD product ion spectra of the monoalkylated isomer 1 of $\mathrm{d}(\mathrm{GC})\left(\mathrm{t}_{\mathrm{r}} 7.4 \mathrm{~min}\right)$ with $[\mathrm{M}-\mathrm{H}]^{-}=823$ resulted in the formation of an ion at $\mathrm{m} / \mathrm{z} 418$, which represents an alkylated guanine residue. Isomer $2\left(t_{r} 8.2 \mathrm{~min}\right)$ represented the $d(G C)$ with alkylation position at the cytosine moiety. This was proven by the occurrence of a product-ion at $\mathrm{m} / \mathrm{z} 378$ which corresponded to an alkylated cytidine residue.

Data from the monoalkylated $\mathrm{d}(\mathrm{GT})$ showed, as expected, only one isomer at the corresponding $\mathrm{m} / \mathrm{z}$ of 837. Alkylation could only be observed at the guanine moiety. In general one can conclude that melphalan alkylation specificity is in the order of $\mathrm{G}>\mathrm{A}>\mathrm{C}(>\mathrm{T})$. This corresponds to earlier published reports $[2,5]$.

\section{Melphalan Alkylation of the 2'- Oligodeoxynucleotides 4-mers}

Reaction mixtures became somewhat more complicated when alkylating a 4-mer such as d(AGCT) as shown in Figure 5. In this case there were three major alkylation positions: At the C- , A-, and G-base. In the corresponding chromatogram one could indeed see three isomers with a $m / z$ of $720\left([\mathrm{M}-\mathrm{H}]^{2-}\right)$. In Figure 5 the low energy CAD product ion spectra are also shown for the three different isomers. The first isomer $\left(t_{r}=13.24 \mathrm{~min}\right)$ showed product ions which corresponded to $\mathrm{w}_{1^{-}}, \mathrm{w}_{2^{-}}$, and $\mathrm{w}_{3}$-fragments. This could only be explained by alkylation of the adenine moiety. The second isomer $\left(t_{\mathrm{r}}\right.$ $=14.06 \mathrm{~min}$ ) had a different fragmentation behavior under low energy CAD conditions; only $\mathrm{w}_{1}$-fragments were observed. Another major fragment was the $\mathrm{a}_{3}-\mathrm{B}_{3}$ fragment indicating that melphalan was positioned at the cytosine base. This assumption was supported by the presence of a product-ion at $\mathrm{m} / \mathrm{z} 878$ corresponding to a $\left[\mathrm{w}_{2}+\mathrm{mel}\right]^{-}$-fragment. The third and major isomer $\left(t_{\mathrm{r}}=15.00 \mathrm{~min}\right.$ ) showed product ions at $\mathrm{m} / \mathrm{z} 321$ and 610 which were assigned to the $\mathrm{w}_{1^{-}}$and $\mathrm{w}_{2}$-fragments. A major product ion was present at $\mathrm{m} / \mathrm{z} 418$ which was explained by a melphalan alkylated guanine base. These data showed that alkylation can occur at any position in an oligodeoxynucleotide chain. The w-ion series showed a good reproducibility to determine a modification site in melphalan treated $2^{\prime}$-ODNs. In spite of the bifunctional alkylation character of melphalan no cross link adducts could be observed. This is in accordance with our earlier published results in which it was stated that melphalan cross linking is not a straightforward process [5]. Also, no bis-alkylated 2'ODNs were detected. 


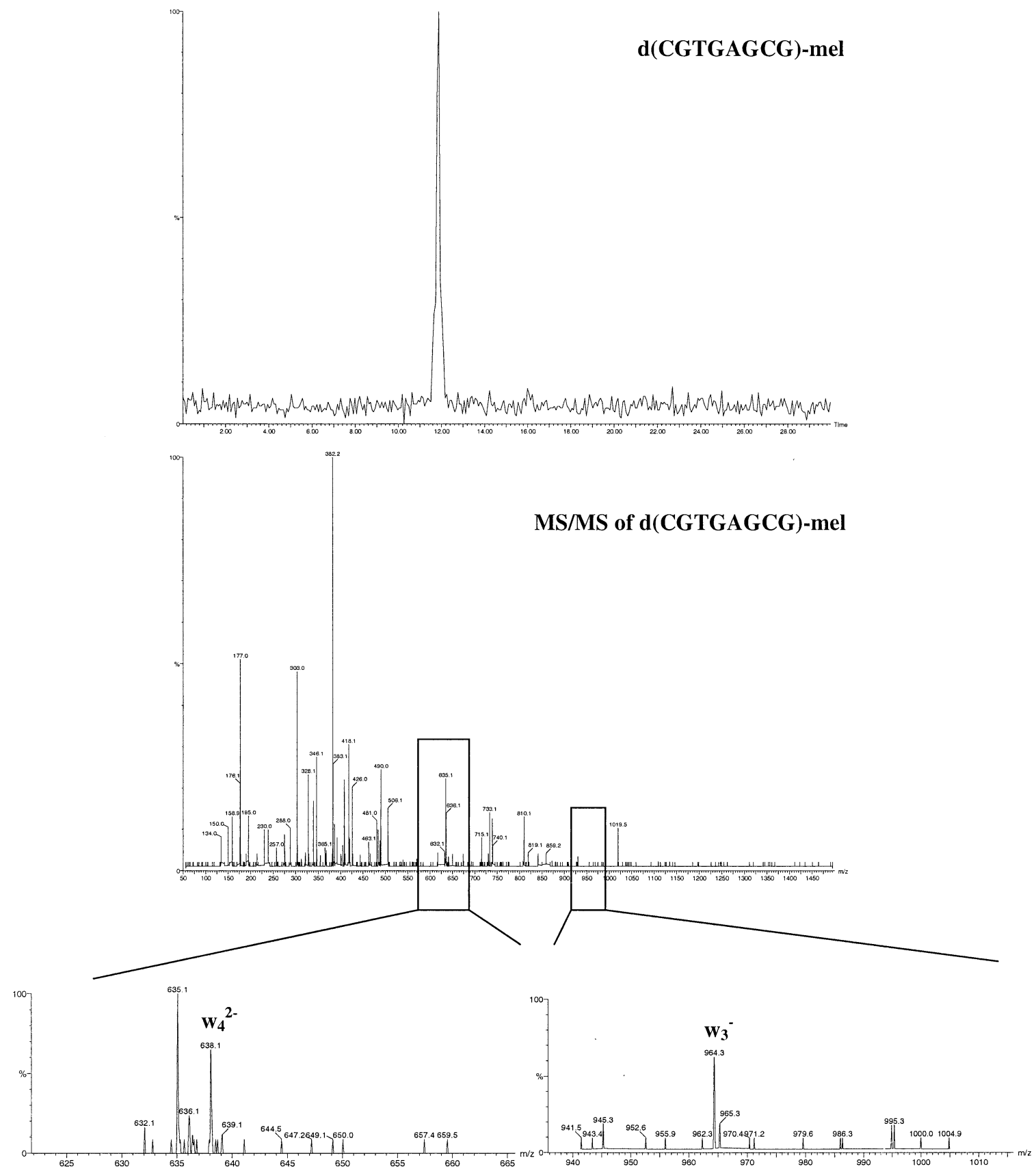

Figure 8. Chromatographic separation of the reaction mixture of the melphalan alkylated octa-mer $\mathrm{d}\left(\right.$ CGTGAGCG) on a reversed phase analytical column $\left(\mathrm{C}_{18}, 300 \mu \mathrm{m}\right.$ i.d., $5 \mathrm{~cm}$ length). Mobile phases consisted of A: $400 \mathrm{mM} \mathrm{HFiP}$ in $\mathrm{H}_{2} \mathrm{O}$ (pH 7); B: $400 \mathrm{mM} \mathrm{HFiP}$ in $\mathrm{MeOH}$ (pH 7); The starting conditions of the mobile phase were $98 \% \mathrm{~A}, 2 \% \mathrm{~B}$. These were maintained for $2 \mathrm{~min}$. Then a linear gradient was started reaching $20 \% \mathrm{~A}, 80 \% \mathrm{~B}$ in $18 \mathrm{~min}$. These conditions were maintained for $10 \mathrm{~min}$. One signal can be seen which represents alkylation on the $G_{4}$-guanine residue. The product-ion spectrum is enlarged in the areas which show the important product-ions $\mathrm{w}^{3-}$ and $\mathrm{w} 4^{2-}$ as discussed in the text.

In the case of the alkylated d(GCGC) two isomers could be observed with respective retention times of $12.95 \mathrm{~min}$ and $16.62 \mathrm{~min}$. (Figure 6). The first isomer $\left([\mathrm{M}-2 \mathrm{H}]^{2-}=720.5\right)$ gave product ions corresponding to $\mathrm{w}_{1^{-}}$and $\mathrm{w}_{2}$-fragments. The $\mathrm{w}_{3}$-fragment was not present but instead a $\left[\mathrm{d}_{1}-\mathrm{H}_{2} \mathrm{O}+\text { mel] }\right]^{-}$-fragment $(\mathrm{m} / \mathrm{z}$ 597) was observed. Moreover, a product ion with $\mathrm{m} / \mathrm{z}$
418 was present which corresponded to an alkylated guanine base. Therefore, it was concluded that melphalan was located at the $5^{\prime}$-endstanding guanine base. In the product ion spectrum of the second isomer, only the $\mathrm{w}_{1}$-ion from the $\mathrm{w}$-series could be observed. Next to this the $\mathrm{a}_{3}-\mathrm{B}_{3}$ - and the $\mathrm{d}_{2}$-ions were very abundant. This, and with a product ion at $\mathrm{m} / \mathrm{z} 418$ (alkylated guanine) 
taken into account, a modification on the guanine moiety at the $3^{\prime}$-position was proposed.

A difference in alkylation preference for both Gresidues could be observed when studying the alkylated $d(G C G C)$. There seemed to be a slight preference for alkylation on the guanine base at the $3^{\prime}$-position. When alkylating $\mathrm{d}(\mathrm{GGGG})$, only one isomer was found which corresponded to an alkylation at the $5^{\prime}$-position. This was proven by the presence of $\mathrm{w}_{1^{-}}, \mathrm{w}_{2^{-}}$, as well as $\mathrm{w}_{3}$-fragments, in combination with the alkylated $\mathrm{a}_{2}-\mathrm{B}_{2}-$ fragment $\left(\left[\mathrm{a}_{2}-\mathrm{B}_{2}+\mathrm{mel}^{-}\right)\right.$. The difference with the $\mathrm{d}(\mathrm{GCGC})$ alkylation study might be explained by the more steric hindered position if $G$ is located between two purines instead of two pyrimidines.

\section{Melphalan Alkylation of the 2'- Oligodeoxynucleotides Hepta-mers}

When studying the low energy product ion spectra of larger 2'-oligodeoxynucleotides it was not always possible to observe the whole series of $\mathrm{w}_{-}, \mathrm{d}-, \mathrm{a}-\mathrm{B}-$, and $\mathrm{y}$-fragments. In addition, product ion spectra had to be taken of the adducted 2'-ODNs, which were present in very low amounts if compared with the amount of unmodified species. Since product ions were already very low abundant in the low energy CAD spectra of the unmodified 2'-ODNs, it was also very difficult to detect them in the product ion spectra of the modified ones. From Table 1 the conclusion could be made that for the hepta-mers almost the whole w-series could be observed (singly and/or doubly charged). Also the yand the a-B-series were almost complete. Only the d-series was limited in the higher mass range $(>900$ a.m.u.). However, an important remark has to be made. The identity of certain series of fragment ions is a general problem when analyzing symmetric sequences, since they generate isobaric $5^{\prime}$ - and $3^{\prime}$-fragment ions. This can also be seen in Table 1. Since we cannot distinguish between these two isobaric series, the $\mathrm{w}$-ion series observed for d(TTTGTTT) can also be the d-ion series. When we take a general look at the characteristics of the product ion spectra of the melphalan reacted hepta-mers d(GTTTTTT), d(TTTGTTT), and d(TTTTTTG) (Figure 7), a great resemblance could be observed. In the case of $\mathrm{d}$ (GTTTTTT) we expected adduct formation on the guanine base only. In the chromatogram only one peak could be detected with a $t_{r}=12.31 \mathrm{~min}$. Low energy CAD product ion spectra of $[\mathrm{M}-4 \mathrm{H}]^{4-}=589.2$ showed an identical $\mathrm{W}$-series compared to the corresponding unmodified 2'-ODN. The $\mathrm{d}_{1}$ - and $\mathrm{d}_{2}$-ions were replaced by $\left[\mathrm{d}_{1}+\text { mel }\right]^{-}$- and $\left[\mathrm{d}_{2}+\mathrm{mell}\right]^{-}$-ions, and could only be observed by enlarging the spectra due to their low abundances. Nevertheless, the data proved alkylation at the 5'endstanding guanine base. If the modified d(TTTGTTT) was fragmented one could see in the lower mass range the $\mathrm{w}$ - and d-ions also observed in the unmodified $2^{\prime}$-ODN. Next to this a product ion at $\mathrm{m} / \mathrm{z} 418$ was present assigned to an alkylated guanine residue. In this case no fragments were present in the higher mass region (>800 a.m.u.), despite the use of very low collision energies $(<15 \mathrm{eV})$. Fragmenting the melphalan-modified d(TTTTTTG) only the d-ions were identical to the unmodified 2'-ODN. The $w_{1}-$ and $w_{2}$-ions were detected as $\left[\mathrm{w}_{1}+\mathrm{mel}\right]^{-}$- and $\left[\mathrm{w}_{2}+\text { mel }\right]^{-}$-ions. This proved that melphalan alkylation occured at the 3 '-end of the sequence. However, these results only proof that our LC-ES MS/MS method is useful in the field of DNA adduct analysis of dODNs. Alkylation sites in the middle as well as at the end of an oligonucleotide chain could be detected.

\section{Melphalan Alkylation of the d(CGTGAGCG) Octamer}

For the adducted octa-mer d(CGTGAGCG) (Figure 8) only one compound was observed with the highest abundance at $[\mathrm{M}-4 \mathrm{H}]^{4-}=678.7$. A major product ion of this compound was detected at $\mathrm{m} / \mathrm{z} 418$ corresponding to a melphalan alkylated guanine residue. Since four guanine bases were present in this $2^{\prime}$-ODN, four possible G-modification sites were available. Comparison of the low energy product ion spectrum of the unmodified and modified d(CGTGAGCG) showed that $\mathrm{w}_{1^{-}}, \mathrm{w}_{2^{-}}, \mathrm{w}_{3^{-}}$, and the doubly charged $\mathrm{w}_{4}$-ions were present in both cases. This meant that the modification was not present in the last four bases A, G, C, and G. In addition there was a major product ion at $\mathrm{m} / \mathrm{z} 1019$ which corresponded to the $\mathrm{a}_{4}-\mathrm{B}_{4}$-fragment. Therefore, alkylation at the first three bases was excluded. The abundance of this fragment was relatively pronounced compared to the same product ion from the unmodified 2'-ODN. This indicated adduct formation on $\mathrm{G}_{4}$ followed by a facilitated depurination, already observed in earlier studies $[4,5,24]$.

\section{Conclusion}

If di-mers or tetra-mers of 2'-ODNs were reacted with melphalan, alkylation could occur at different positions in the chain. In most cases we were able to separate the isomers of the small modified 2'-ODNs. Undertaking this study, additional information on the melphalan alkylation specificity was gathered. For this reason, this study is complementary to our earlier performed in vitro and in vivo studies. By choosing a specific oligodeoxynucleotide sequence a difference in alkylation specificity was seen: Interpreting the ES-MS and ESMS/MS data of alkylated d(GG), d(GA), d(GC), and $\mathrm{d}(\mathrm{GT})$ one could notice that two isomers were formed in $d(G G), d(G A)$, and $d(G C)$. In general one can conclude that melphalan alkylation specificity is in the order of $\mathrm{G}$ $>\mathrm{A}>\mathrm{C}(>>\mathrm{T})$. When studying larger unmodified and modified 2'-ODNs, it was observed that melphalan alkylation only occurred at specific positions in the chain, more precisely at the guanine moiety. The study 
of the alkylation site in a melphalan treated octamer revealed the presence of $G$ alkylation.

In spite of the bifunctional alkylation character of melphalan, no cross link adducts could be observed. This is in accordance with earlier published results stating that cross linking by melphalan is not a straightforward process [5]. Also, no bis-alkylated 2'-ODNs were detected.

\section{Acknowledgments}

The authors acknowledge the Foundation for Scientific Research Flanders (FWO-Vlaanderen) for a grant. BVdD is especially indebted to the IWT for a grant. The authors also thank the University of Antwerp and the Flemish government (GOA-action) for financial support. They acknowledge Jef Schrooten for technical support.

\section{References}

1. Hemminki, K.; Koskinen, M.; Rajaniemi, H.; Zhao, C. DNA Adducts, Mutations, and Cancer 2000. Reg. Toxicol. Pharmacol. 2000, 32, 264-275.

2. Furner, R. L.; Brown, R. K. L-Phenylalanine Mustard (LPam)-the First 25 Years. Cancer Treat. Rep. 1980, 64, 559-574.

3. Mattes, W. B.; Hartley, J. A.; Kohn, K. W. DNA Sequence Selectivity of Guanine-N7 Alkylation by Nitrogen Mustards. Nucleic Acids Res. 1986, 14, 2971-2987.

4. Hoes, I.; Lemiere, F.; Van Dongen, W.; Vanhoutte, K.; Esmans, E. L.; Van Bockstaele, D.; Berneman, Z.; Deforce, D.; Van den Eckhout, E. G. Analysis of Melphalan Adducts of 2'-Deoxynucleotides in Calf Thymus DNA Hydrolysates by Capillary High Performance Liquid Chromatography-Electrospray Tandem Mass Spectrometry. J. Chromatogr. B Biomed. Sci. Appl. 1999, 736, 43-59.

5. Van den Driessche, B.; Lemière, F.; Van Dongen, W.; Esmans, E. L. Alkylation of DNA by Melphalan: Investigation of Capillary Liquid Chromatography-Electrospray Ionization Tandem Mass Spectrometry in the Study of the Adducts at the Nucleoside Level. J. Chromatogr. B Anal. Technol. Biomed. Life Sci. 2003, 785, 21-37.

6. Esmans, E. L.; Broes, D.; Hoes, I.; Lemière, F.; Vanhoutte, K. Liquid Chromatography-Mass Spectrometry in Nucleoside, Nucleotide, and Modified Nucleotide Characterization. J. Chromatogr. A. 1998, 794, 109-127.

7. Brown, K.; Harvey, C. A.; Turteltaub, K. W.; Shields, S. J. Structural Characterization of Carcinogen-Modified Oligodeoxynucleotide Adducts Using Matrix-Assisted Laser Desorption/Ionization Mass Spectrometry. J. Mass Spectrom. 2003, 38, $68-79$.

8. Kirpekar, F.; Nordhoff, E.; Larsen, L. K.; Kristiansen, K.; Roepstorff, P.; Hillenkamp, F. DNA Sequence Analysis by MALDI Mass Spectrometry. Nucleic Acids Res. 1998, 26, 25542559.

9. Glover, R. P.; Sweetman, G. M.; Farmer, P. B.; Roberts, G. C. Sequencing of Oligonucleotides Using High Performance Liquid Chromatography and Electrospray Mass Spectrometry. Rapid Commun. Mass Spectrom. 1995, 9, 897-901.
10. Covey, T. R.; Bonner, R. F.; Shushan, B. I.; Henion, J. The Determination of Protein, Oligonucleotide, and Peptide Molecular Weights by Ion-Spray Mass Spectrometry. Rapid Commun. Mass Spectrom. 1988, 2, 249-256.

11. Potier, N.; Van Dorsselaer, A.; Cordier, Y.; Roch, O.; Bischoff, R. Negative Electrospray Ionization Mass Spectrometry of Synthetic and Chemically Modified Oligonucleotides. Nucleic Acids Res. 1994, 22, 3895-3903.

12. McLuckey, S. A.; Wu, J.; Bundy, J. L.; Stephenson, J. L., Jr.; Hurst, G. B. Oligonucleotide Mixture Analysis via Electrospray and Ion/Ion Reactions in a Quadrupole Ion Trap. Anal. Chem 2002, 74, 976-984.

13. Wan, K. X.; Gross, M. L. Fragmentation Mechanisms of Oligodeoxynucleotides: Effects of Replacing Phosphates with Methylphosphonates and Thymines with Other Bases in TRich Sequences. J. Am. Soc Mass Spectrom. 2001, 12, 580-589.

14. Wan, K. X.; Gross, J.; Hillenkamp, F.; Gross, M. L. Fragmentation Mechanisms of Oligodeoxynucleotides Studied by H/D Exchange and Electrospray Ionization Tandem Mass Spectrometry. J. Am. Soc Mass Spectrom. 2001, 12, 193-205.

15. Wang, Y.; Taylor, J. S.; Gross, M. L. Fragmentation of Photomodified Oligodeoxynucleotides Adducted with Metal Ions in an Electrospray-Ionization Ion-Trap Mass Spectrometer. J. Am. Soc Mass Spectrom. 2001, 12, 1174-1179.

16. Wang, Y.; Taylor, J. S.; Gross, M. L. Fragmentation of Electrospray-Produced Oligodeoxynucleotide Ions Adducted to Metal Ions. J. Am. Soc Mass Spectrom. 2001, 12, 550-556.

17. Wang, Z.; Wan, K. X.; Ramanathan, R.; Taylor, J. S.; Gross, M. L. Structure and Fragmentation Mechanisms of Isomeric T-Rich Oligodeoxynucleotides: A Comparison of Four Tandem Mass Spectrometric Methods. J. Am. Soc Mass Spectrom. 1998, 9, 683-691.

18. Ni, J.; Pomerantz, C.; Rozenski, J.; Zhang, Y.; McCloskey, J. A. Interpretation of Oligonucleotide Mass Spectra for Determination of Sequence Using Electrospray Ionization and Tandem Mass Spectrometry. Anal. Chem 1996, 68, 1989-1999.

19. Rozenski, J.; McCloskey, J. A. Determination of Nearest Neighbors in Nucleic Acids by Mass Spectrometry. Anal. Chem 1999, 71, 1454-1459.

20. Apffel, A.; Chakel, J. A.; Fischer, S.; Lichtenwalter, K.; Hancock, W. S. New Procedure for the Use of High Performance Liquid Chromatography Electrospray Ionization Mass Spectrometry for the Analysis of Nucleotides and Ooligonucleotides. J. Chromatogr. A 1997, 777, 3-21.

21. Apffel, A.; Chakel, J. A.; Fischer, S.; Lichtenwalter, K.; Hancock, W. S. Analysis of Oligonucleotides by HPLC-Electrospray Ionization Mass Spectrometry. Anal. Chem. 1997, 69, 1320-1325.

22. Boschenok, J.; Sheil, M. M. Electrospray Tandem Mass Spectrometry of Nucleotides. Rapid Commun. Mass Spectrom. 1996, 10, 144-149.

23. McLuckey, S. A.; Glish, G. L.; Van Berkel, G. J. Charge Determination of Product Ions Formed from Collision-Induced Dissociation of Multiply Protonated Molecules via Ion/Molecule Reactions. Anal. Chem 1991, 63, 1971-1978.

24. Hoes, I.; Van Dongen, W.; Lemiere, F.; Esmans, E. L.; Van Bockstaele, D.; Berneman, Z. N. Comparison Between Capillary and Nano Liquid Chromatography-Electrospray Mass Spectrometry for the Analysis of Minor DNA Melphalan Adducts. J. Chromatogr. B Biomed. Sci. Appl. 2000, 748, 197-212. 